\title{
Rancang Bangun Sistem Monitoring dan Kendali Daya Listrik pada Rumah Kos Menggunakan NodeMCU dan Firebase Berbasis Android
}

\author{
Achmad Furqon ${ }^{1}$, Agung Budi Prasetijo ${ }^{2}$, Eko Didik Widianto ${ }^{3}$ \\ Departemen Teknik Komputer, \\ Fakultas Teknik, \\ Universitas Diponegoro \\ 1furqon@student.undip.ac.id, ²agungprasetijo@ce.undip.ac.id, ${ }^{3}$ didik@live.undip.ac.id
}

\begin{abstract}
Ringkasan
Pada makalah ini dibuat suatu sistem yang digunakan untuk memantau daya listrik yang dipakai oleh penyewa kos serta menghitung besarnya energi yang digunakan dan juga tarif yang dikenakan. Sistem dirancang menggunakan modul NodeMCU yang akan dipasangkan dengan sensor PZEM-004t dan relay. NodeMCU berfungsi untuk pengiriman data ke database. Sensor PZEM-004t digunakan untuk membaca tegangan dan arus listrik yang mengalir sehingga bisa didapatkan nilai daya. Relay digunakan sebagai kontrol untuk memutus sambungan listrik dika diperlukan. Dan untuk mengetahui daya listrik tersebut data daya akan dikirimkan ke Realtime Database Firebase yang akan diakses oleh perangkat Android melalui internet sehingga sistem monitoring ini dapat dilakukan secara jarak jauh. Hasil pengukuran sensor menunjukan akurasi kesalahan sebesar $\pm 1,8 \%$ dengan pembanding multimeter digital. Hasil pengujian aplikasi sistem menunjukan aplikasi dapat memantau daya pada tiap kamar kos secara realtime.
\end{abstract}

Kata kunci: Sistem monitoring, NodeMCU, PZEM-004t, Firebase, Android

\section{Pendahuluan}

Di daerah perkotaan banyak orang berdatangan dari berbagai daerah dengan tujuan bekerja maupun menuntut ilmu. Warga perkotaan menangkap peluang tersebut dengan menjalankan bisnis penyewaan kamar atau kos-kosan untuk tempat tinggal. Dalam menyewa kos terkadang seseorang membawa banyak barang elektronik yang mereka miliki akibatnya pemakaian listrik semakin tinggi. Oleh karena itu pemilik kos akan mengalami kerugian apabila pengeluaran biaya operasional yang termasuk listrik tersebut lebih tinggi daripada pemasukan uang sewa yang diterima dari penyewa kos.

Berdasarkan latar belakang tersebut dirancang sistem yang dapat memantau daya listrik yang digunakan oleh penyewa kos dan dapat mengontrol sambungan listrik. Dan juga sistem ini menggunakan teknologi Internet of Things agar sistem monitoring dapat dilakukan secara jarak jauh menggunakan perangkat android. 


\section{Kajian Pustaka}

Terdapat beberapa sistem yang bertujuan hampir sama yang telah dirancang dan dikembangkan sebelumnya dengan menggunakan berbagai macam cara dan perangkat yang digunakan. Pada bab ini akan dijelaskan beberapa penelitian dahulu sebagai acuan dan perbandingan.

\subsection{Kendali Perangkat Listrik dan Monitoring Daya pada MCB Berbasis TCP/IP [1]}

Penelitian ini bertujuan untuk membuat suatu sistem yang dapat mengendalikan sistem kendali perangkat listrik dan monitoring daya pada MCB berbasis TCP/IP dan juga dibuat bertujuan untuk memudahkan para pengguna listrik untuk mengendalikan perangkat listrik dan dapat memonitoring daya yang digunakan dari jarak jauh. Monitoring dalam hal ini adalah bagaimana melakukan monitoring daya pada perangkat listrik. Proses perancangan Sistem yang dibuat ini terdiri dari beberapa komponen diantaranya mikrokontroler Arduino Uno yang berfungsi sebagai pengontrol, CT sensor sebagai pembaca daya, ethernet shield sebagai penghubung jaringan, relay sebagai saklar. Hasil dari penelitian ini adalah sistem pengendali perangkat listrik dan memonitoring daya pada MCB secara jarak jauh. Dengan cara mikrokontroler arduino dihubungkan dengan ethernet shield dan relay agar bisa diakses pada web yang telah ditanamkan pada mikrokontroler. Sehingga dengan adanya sistem ini pengguna dapat mengendalikan dan mengontrol baik menghidupkan maupun mematikan perangkat listrik dari tempat manapun.

\subsection{Prototype Sistem Monitoring Masa Sewa Kamar Kos Berbasis Mikrokontroler [2]}

Penelitian ini dibuat suatu sistem yang dapat mendata penyewa kamar kos dan dapat memberikan tindakan tertentu jika masa sewanya telah habis secara otomatis. Penelitian ini memanfaatkan teknologi antarmuka komputer dan embedded system menggunakan mikrokontroler. Antarmuka komputer mendata penyewa kamar kos, ketika masa sewanya akan habis maka komputer akan memerintahkan mikrokontroler untuk memberi peringatan berupa lampu indikator dan buzzer, selanjutnya akan memutuskan aliran listrik pada kamar tersebut menggunakan relay. Hasil pengujian menunjukkan jika masa sewa masih lebih dari 3 hari kamar dalam keadaan normal, jika masa sewa tersisa 3 sampai 0 hari LED indikator berkedip. Jika masa sewa melewati 1 sampai 3 hari maka LED indikator berkedip dan buzzer berbunyi, selanjutnya jika masa sewa lewat dari 3 hari maka relay memutuskan aliran listrik. Jika masa sewa masih masuk masa peringatan kemudian penyewa kamar kos segera melunasi dan operator menambah lagi masa sewa, maka kondisi kamar kembali normal. Alat ini dapat bekerja dengan baik dan bermanfaat untuk mempermudah penagihan dan pendataan penyewa kamar kos.

\subsection{Rancang Bangun Sistem Monitoring Daya Listrik Pada Kamar Kos Berbasis Internet of Things (IoT) [3]}

Penelitian ini menjelaskan tentang dalam menggunakan peralatan listrik setiap kamar kos diperlukan alat untuk memonitoring penggunaan daya listrik, agar penggunaan daya listrik pada kamar kos ini sesuai dengan daya yang dibutuhkan. Oleh karena itu dirancang alat yang dapat mempermudah melakukan aktivitas memantau pemakaian daya listrik yang hasilnya dapat ditampilkan melalui LCD 16x2 dan dapat diinformasikan melalui internet. Tujuan penelitian ini adalah merancang bangun sistem 
monitoring daya listrik berbasis IoT untuk mempermudah memantau penggunaan daya listrik pada kamar kos berbasis IoT.

\subsection{Implementasi Sistem Monitoring Daya Listrik Berbasis Web dan Protokol Komunikasi Websocket [4]}

Pada penelitian ini, dikembangkan sebuah sistem monitoring daya listrik yang dipasang pada terminal listrik di sebuah ruangan dengan menggunakan sensor arus current transformer (CT) sensor YHDC SCT-013-000 dan mikrokontroler NodeMCU. Nantinya, perangkat listrik yang terhubung pada terminal listrik tersebut akan dipantau penggunaan daya listriknya. Data monitoring daya listrik dari perangkat monitoring akan dikirimkan dengan menggunakan protocol komunikasi Websocket yang selanjutnya akan disimpan pada database server. Sedangkan untuk data monitoring daya listrik ditampilkan pada antarmuka web. Dengan begitu, diharapkan pengguna dapat melakukan monitoring daya listrik pada ruangan dengan lebih mudah dan akurat. Hal ini berdasarkan hasil pengujian yang telah dilakukan, didapat akurasi pengukuran arus listrik hingga 97,14\%, akurasi tegangan listrik hingga 99\%, dan akurasi perhitungan daya listrik mencapai $98 \%$. Untuk performa penerimaan data monitoring daya listrik yang didapat membutuhkan waktu rata-rata sebesar 160,8 milidetik. Sedangkan untuk web monitoring daya listrik yang dibangun mampu menampilkan penggunaan daya listrik hingga estimasi biaya penggunaan listrik pada setiap perangkat monitoring.

\subsection{Monitoring Menggunaan Daya Listrik Sebagai Implementasi Internet of Things Berbasis Wireless Sensor Network [5]}

Penelitian ini adalah rancang bangun wireless node sensor yang bisa mengukur parameter listrik arus bolak-balik (AC) seperti tegangan efektif, arus efektif, daya aktif, daya semu, faktor daya dan jumlah pemakaian energi listrik dengan menggunakan modul ESP8266 sebagai penghubung dengan jaringan Wi-Fi. Perhitungan parameterparameter listrik yang diperoleh dari pembacaan ADC mikrokontroler ATmega328P dari transformator step down yang digunakan sebagai sensor tegangan dan sensor SCT013 yang digunakan sebagai sensor arus listrik AC akan ditransmisikan ke server melalui jaringan Wi-Fi dari suatu Access Point (AP). Modul ESP8266 yang diprogram menggunakan ATCommand terbukti secara handal dapat mengirimkan data ukur secara bersamaan dengan format data serial dari wireless node sensor ke suatu server menggunakan protocol TCP/IP. Monitoring penggunaan daya listrik melalui internet yang dirancang pada penelitian, baik melalui aplikasi Android maupun web browser terbukti secara handal mampu menampilkan beberapa parameter listrik dengan data yang sama dibandingkan dengan rekapan data logger yang diambil dari SD-Card yang terpasang pada wireless node sensor.

\subsection{NodeMCU [6]}

NodeMCU pada dasarnya adalah pengembangan dari ESP8266 dengan firmware berbasis e-Lua. Pada NodeMcu dilengkapi dengan micro usb port yang berfungsi untuk pemorgaman maupun power supply. Selain itu juga pada NodeMCU di lengkapi dengan tombol push button yaitu tombol reset dan flash. NodeMCU menggunakan bahasa pemorgamanan Lua yang merupakan package dari ESP8266. Bahasa Lua memiliki logika dan susunan pemorgaman yang sama dengan c hanya berbeda syntax. 


\section{$2.7 \quad$ PZEM-004t [7]}

PZEM-004T adalah sebuah sensor yang dapat digunakan untuk mengukur arus, tegangan, daya dan energi pada suatu kabel yang dialiri listrik. Sensor dapat ini digunakan pada Arduino, ESP6288, Raspberry Pi atau opensource platform lainnya. Sensor ini memiliki dimensi $31 \times 74 \mathrm{~mm}$, dan memiliki modul trafo arus berdiameter 33 $\mathrm{mm}$.

\subsection{Relay [8]}

Relay adalah saklar (switch) elektrik yang bekerja berdasarkan medan magnet. Relay terdiri dari suatu lilitan dan saklar mekanik. Saklar mekanik akan bergerak jika ada arus listrik yang mengalir melalui lilitan. Dan Susunan kontak pada relay adalah normally open yang akan menutup bila dialiri arus listrik, dan normally close yang akan membuka bila dialiri arus listrik. Kemudian changeover adalah relay memiliki kontak tengah yang akan melepaskan diri dan membuat kontak lainnya berhubungan. Relay digunakan untuk pensaklaran arus atau tegangan listrik yang besar dengan hanya memerlukan arus dan tegangan yang kecil. Relay dapat berfungsi sebagai pengatur logika kontrol untuk suatu sistem.

\section{$2.9 \quad$ Firebase [9]}

Firebase adalah platform seluler yang membantu developer mengembangkan aplikasi berkualitas tinggi secara cepat, berbasis pengguna, dan dapat menghasilkan uang lebih banyak. Firebase terdiri dari fitur pelengkap yang bisa dipadukan sesuai dengan kebutuhan (Google). Digunakannya firebase, karena platform yang telah dikembangkan oleh Google ini memiliki fitur cukup mumpuni untuk dimanfaatkan pada beberapa aplikasi.

\subsection{Android [10]}

Android adalah sebuah sistem operasi pada handphone yang bersifat terbuka dan berbasis pada system operasi Linux. Android bisa digunakan oleh setiap orang yang ingin menggunakannya pada perangkat mereka. Android menyediakan platform terbuka bagi para pengembang untuk menciptakan aplikasi mereka sendiri yang akan digunakan untuk bermacam peranti bergerak. Awalnya, Google Inc. membeli Android Inc., pendatang baru yang membuat peranti lunak untuk ponsel.

\section{Perancangan dan Penerapan}

\section{1. $\quad$ Prinsip Kerja Sistem Monitoring dan Kendali}

Prinsip kerja dari sistem yang dirancang adalah sistem dapat melakukan fungsi monitor pada kamar kos secara nirkabel. Sistem meliputi mikrokontroller NodeMCU sebagai pusat untuk mengolah data dan mengirimnya ke database, database yang berfungsi untuk menyimpan data hasil monitor data nilai daya menggunakan Realtime database Firebase. Fungsi monitor meliputi daya listrik tiap kamar yang didapat dari sensor arus dan tegangan PZEM-004t. Sedangkan untuk pemutusan sambungan listrik menggunakan relay shield.

Data daya didapat perkalian antara data arus dan tegangan yang diperoleh dari sensor PZEM-004t. Data daya tersebut akan dikirimkan oleh NodeMCU ke Firebase melalui wifi kos yang terhubung ke Internet. Pada Firebase akan tersimpan data daya, 
waktu yang meliputi tanggal hingga jam dan juga status kondisi listrik tersambung atau terputus. Kemudian pemilik kos dapat melihat data tersebut menggunakan aplikasi android yang terhubung dengan Firebase yang digunakan. Di dalam aplikasi android tersebut pemilik kos dapat mengetahui daya pada setiap kamar dan mengetahui pemakaian daya yang telah berlalu sampai saat ini dalam bentuk grafik. Serta pemilik kos juga dapat mengontrol untuk memutuskan sambungan listrik dengan memberi perintah off pada relay. Gambar 1 menunjukkan diagram blok sistem secara keseluruhan.

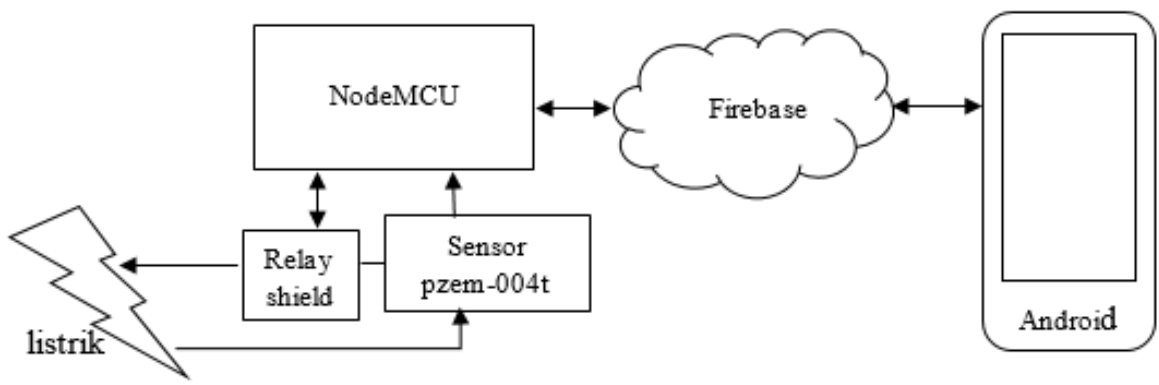

Gambar 1. Diagram Blok prinsip kerja Sistem

\subsection{Perangkat keras Sistem}

Dalam perancangan sistem menggunakan modul NodeMCU dengan mikrokontroler ESP8266 sebagai pusat kendali untuk membaca nilai dari sensor dan mengirim data ke database. Sistem bekerja dengan menggunakan catu daya $5 \mathrm{~V}$ untuk perangkat NodeMCU. Sistem menggunakan bahasa pemrograman C yang diterapkan pada perangkat lunak aplikasi Arduino IDE. Sistem bekerja dengan Sensor Arus PZEM-004T untuk memberikan masukan data arus listrik yang mengalir. Sistem bekerja dengan relay shield untuk mengendalikan data sambungan dari aliran listrik yang berupa on/off. Purwarupa berupa 2 buah kotak dengan setiap kotak memiliki 1 sistem sendiri. Gambar 2 merupakan diagram blok perangkat keras sistem.

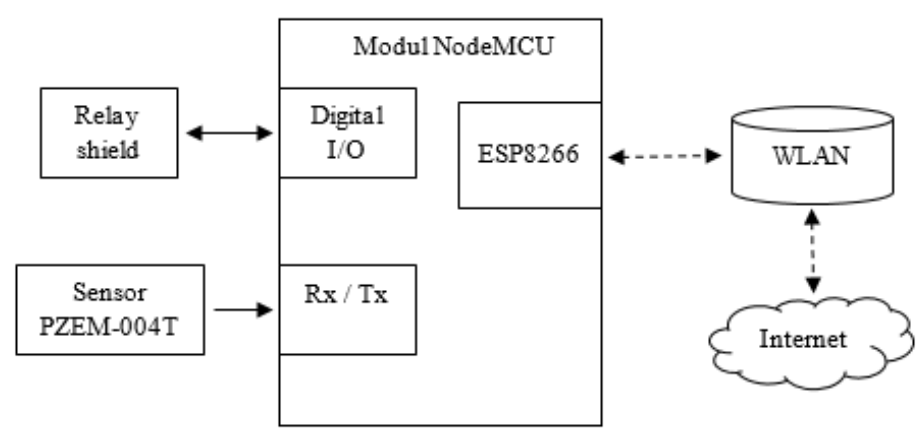

Gambar 2. Diagram Blok perangkat keras sistem

Pusat Pusat kendali sistem menggunakan papan NodeMCU dengan mikrokontroler ESP8266. Komponen yang terhubung dengan sistem diantaranya adalah Relay sebagai kontrol sambungan listrik, sensor arus PZEM-004T sebagai pembaca arus yang mengalir dan modul wifi pada ESP8266 untuk menyambungkan perangkat ke Wireless LAN yang telah terhubung ke internet sehingga perangkat dapat terhubung ke Firebase. Tabel 1 menunjukkan antarmuka pin NodeMCU dengan komponen pada sistem. 
Tabel 1. Antarmuka pin Arduino dengan komponen

\begin{tabular}{|c|c|}
\hline $\begin{array}{c}\text { Antarmuka Pin } \\
\text { NodeMCU }\end{array}$ & Antarmuka Pin Komponen \\
\hline $3.3 \mathrm{~V}$ & VCC PZEM dan Relay \\
\hline RX & TX PZEM-004t \\
\hline TX & RX PZEM-004t \\
\hline D1 & D1 Relay \\
\hline GND & GND PZEM dan Relay \\
\hline
\end{tabular}

\subsection{Perangkat lunak Sistem}

Perancangan perangkat lunak Mikrokontroller akan berisi penjelasan tahapan dalam pembuatan sistem berupa program yang mngendalikan perangkat keras. Sistem yang dibangun mampu membaca masukan dari sensor arus setiap waktu tertentu, mampu mengontrol kondisi dari relay yang kemudian dikirimkan oleh ESP8266 ke Firebase dan menyimpannya pada database dan memberikan umpan balik ke sistem kemudian relay akan mengeksekusi perintah.

Pada diagram alir perancangan perangkat lunak, hal pertama yang dilakukan adalah pemanggilan pustaka yang dibutuhkan dalam program, yaitu pustaka ESP8266 dan Arduino Firebase. Selanjutnya adalah mendefinisikan variabel dan konstanta yang digunakan pada program. Proses berikutnya adalah proses void setup() dimana perintah-perintah dalam proses ini hanya diproses sekali. Proses terakhir adalah void loop(), dimana perintah di dalam proses ini akan dijalankan secara berulang kali. Gambar 3 merupakan diagram alir void setup (). Gambar 4 merupakan diagram alir void loop ().

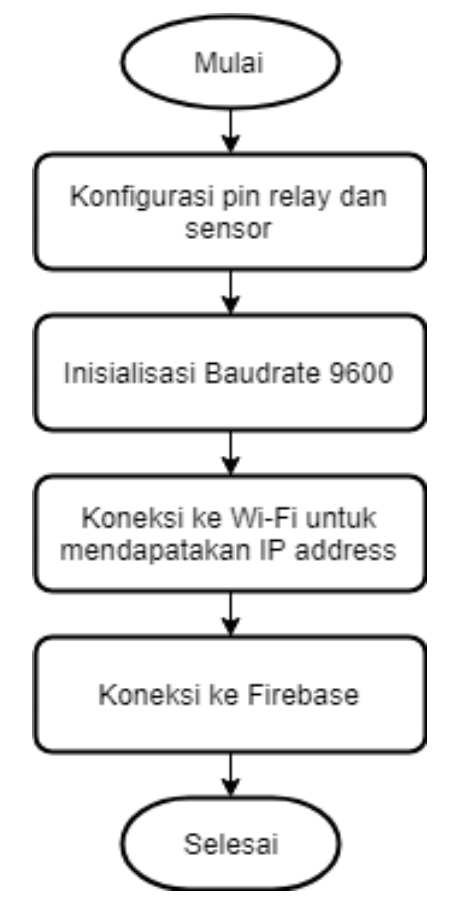

Gambar 3. Diagram alir void setup ()

Pada void setup (), yang dieksekusi pertama adalah perintah untuk konfigurasi pin Relay dan sensor PZEM-004T. Pada proses ini dideklarasikan pin-pin yang digunakan sehingga dapat diidentifikasi oleh mikrokontroler. Proses selanjutnya adalah proses 
inisialisasi komunikasi serial. Komunikasi serial adalah komunikasi antara mikrokontroler dengan komputer dengan port serial dengan baudrate 9600. Baudrate merupakan kecepatan transmisi data serial dengan satuan bit per detik. Berikutnya merupakan proses inisialisasi koneksi dengan jaringan pada Wi-Fi untuk mendapatkan IP Address. Proses ini menghubungkan ke jaringan yang sudah didefinisikan SSID dan password pada perangkat Wi-Fi yang digunakan. Selanjutnya adalah inisialisasi koneksi ke Firebase agar sistem selalu terhubung pada Firebase secara realtime.

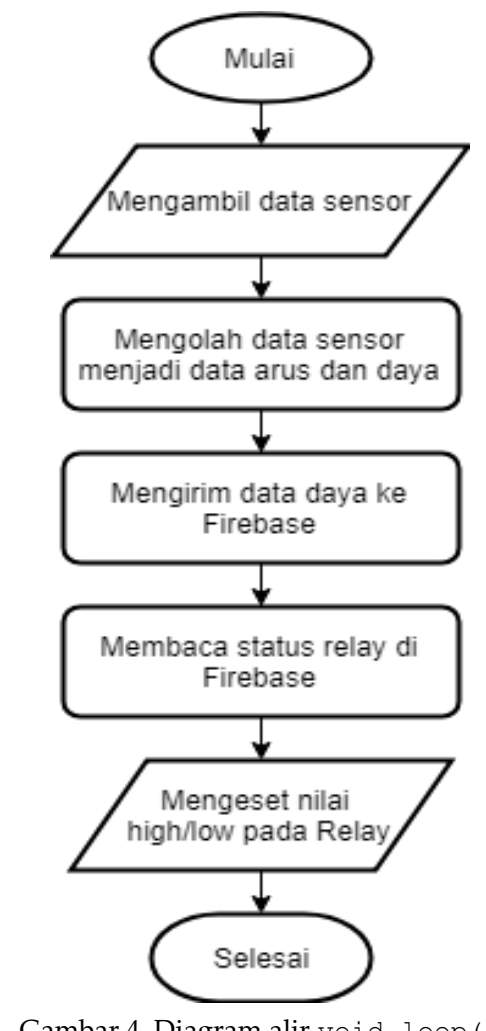

Gambar 4 menjelaskan tentang diagram alir void loop () dimana sistem berjalan secara terus menerus. Pertama kali sistem akan melakukan pengambilan data pada sensor kemudian diolah dan dihitung menggunakan rumus yang ada untuk mendapatkan nilai arus dan daya. Nilai daya yang didapat lalu dikirimkan ke Firebase dengan menyertakan waktu saat pengiriman. Setelah itu sitem mengambil data status Relay pada Firebase kemudian mengeset nilai Relay pada sistem sesuai data pada Firebase.

Diagram Aktivitas menggambarkan workflow (aliran kerja) atau aktivitas dari sebuah sistem atau proses tugas. Activity diagram menggambarkan aktivitas yang dapat dilakukan oleh sistem bukan apa yang dilakukan aktor. Dalam beberapa hal, Diagram Aktivitas memainkan peran mirip diagram alir, tetapi perbedaan prinsip antara notasi diagram alir adalah Diagram Aktivitas mendukung kelakuan (behavior) paralel. Pembuatan Diagram Aktivitas menggunakan perangkat lunak Visual Paradigm Community edition. Berikut adalah Diagram Aktivitas dari Aplikasi Sistem Monitoring Daya Kamar Kos.

Gambar 5 menggambarkan Diagram Aktivitas pada halaman home. Urutan aktifitas setiap fungsi pada halaman home dapat dilihat pada gambar berikut 


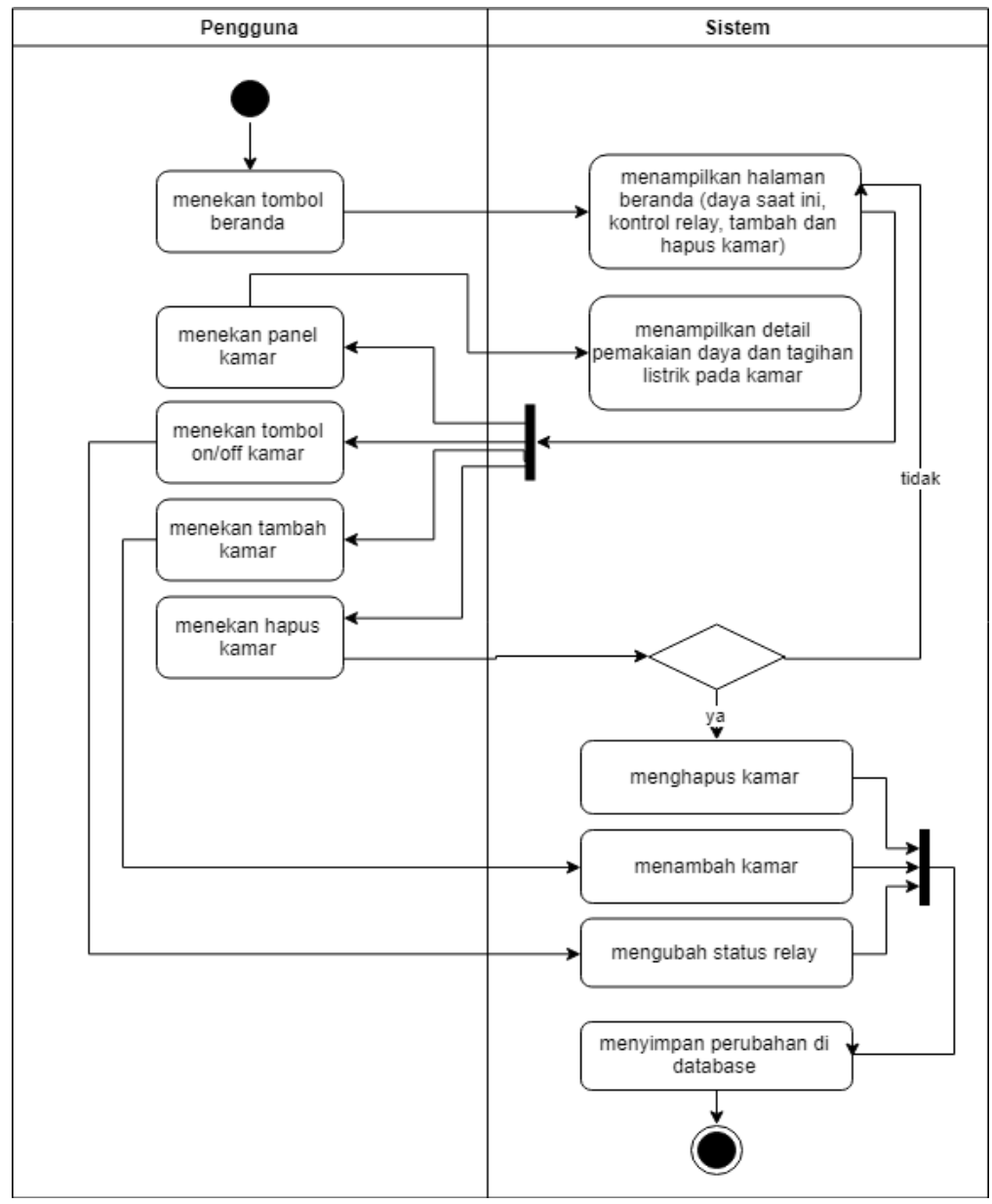

Gambar 5. Diagram Aktivitas Home

Gambar 6 menggambarkan Diagram Aktivitas dari halaman history. Urutan aktifitas dimulai dari menekan halaman history lalu memilih kamar kemudian memasukan tanggal yang diinginkan

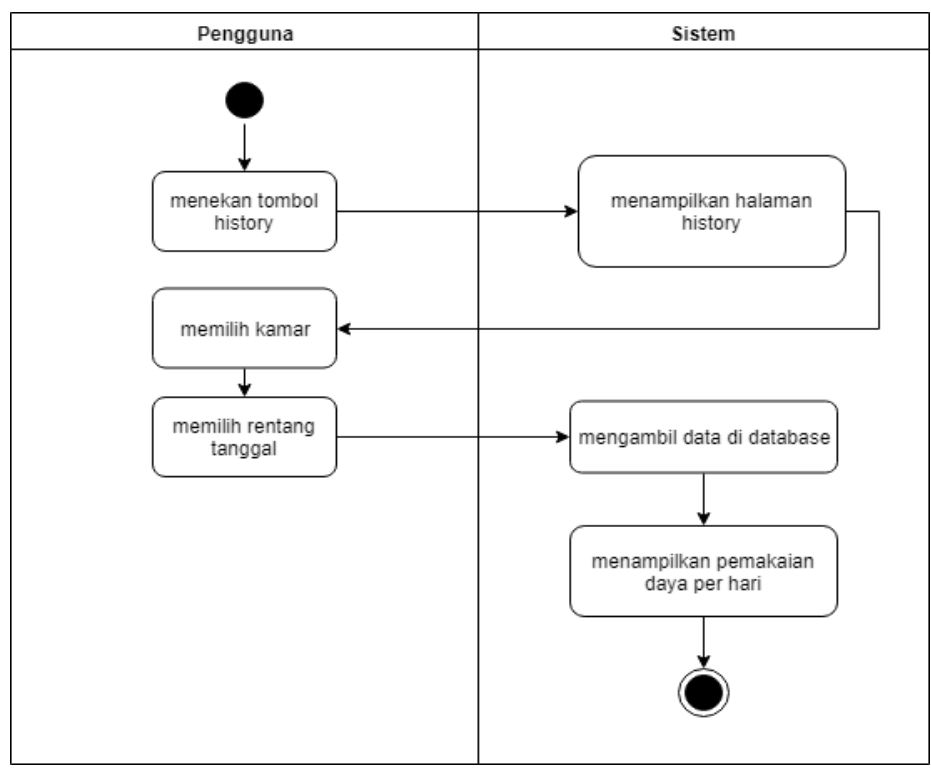

Gambar 6. Diagram Aktivitas History 
Gambar 7 menggambarkan Diagram Aktivitas dari setting. Pada halaman ini terdapat aktifitas untuk mengatur kontrol listrik otomatis, membatasi maksimal daya, menentukan tarif tagihan serta mengatur notifikasi.

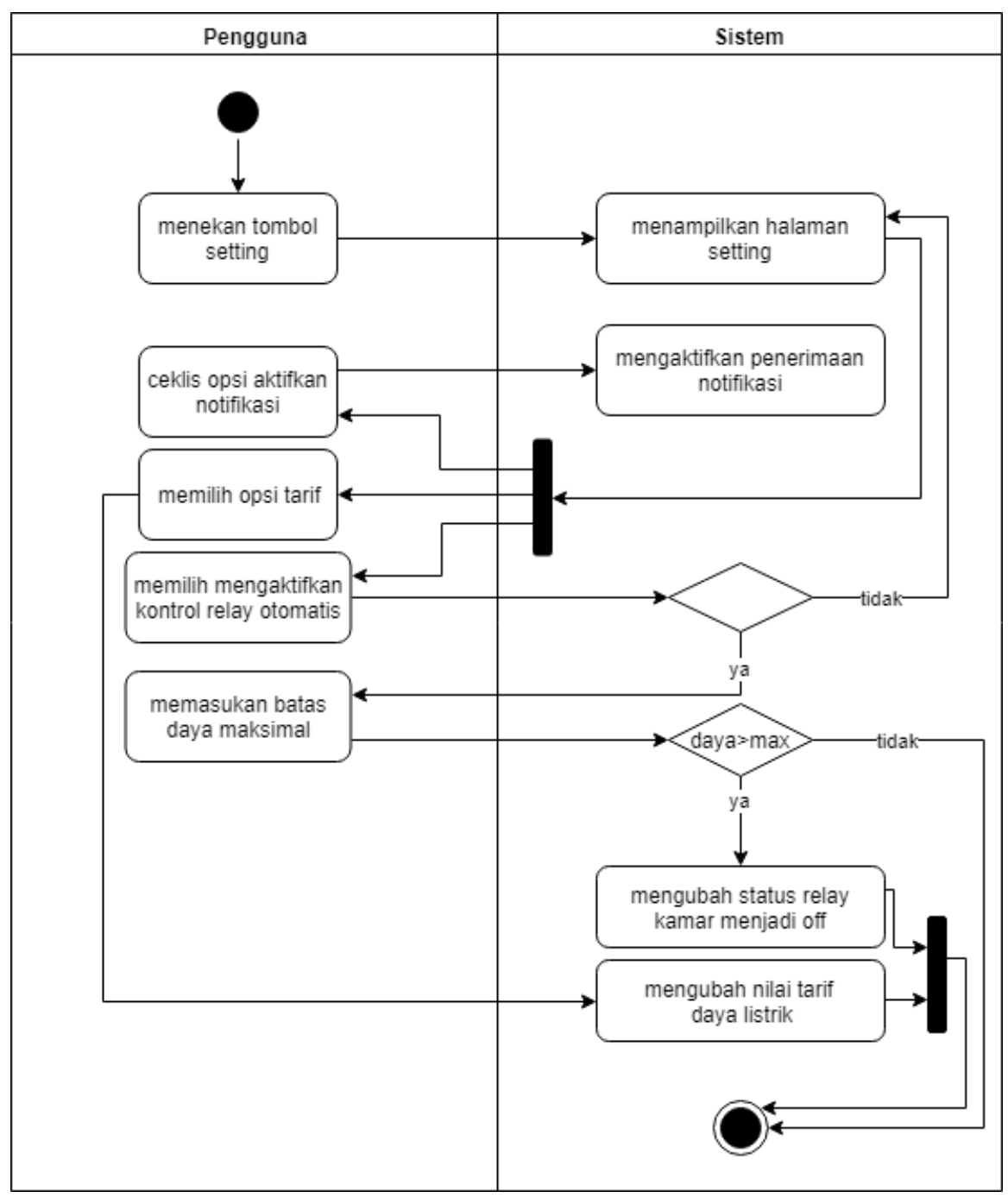

Gambar 7. Diagram Aktivitas Settings

Implementasi antarmuka aplikasi android menjelaskan tampilan halaman aplikasi pada sisi user yang telah dibangun. Aplikasi ini dapat berjalan pada perangkat android versi 5.0 ke atas. Aplikasi ini harus terhubung dengan internet agar dapat mengakses database pada Firebase. Berikut ini merupakan hasil penerjemahaan perancangan aplikasi ke dalam kode program sehingga menghasilkan antarmuka yang diharapkan. Gambar 8 menunjukkan tampilan halaman menu pada aplikasi Sistem Monitoring Daya Listrik pada Kos. 


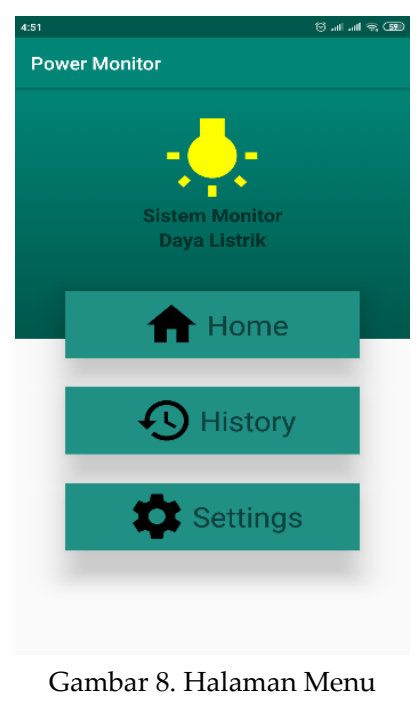

\section{Pengujian dan Pembahasan}

Pengujian sistem dilakukan dengan pengujian terhadap pembacaan nilai dari masing-masing perangkat masukan. Kemudian dilakukan pengujian terhadap perangkat luaran sistem, dan yang terakhir adalah pengujian sistem secara keseluruhan supaya dapat memenuhi semua kebutuhan fungsional sistem.

Pengujian pembacaan sensor dilakukan dengan membandingkan sistem dengan alat ukur yang tersedia. Pengujian ini digunakan untuk mengetahui apakah sensor dapat membaca arus dan tegangan dengan akurat atau tidak. Pengujian dilakukan dengan memberikan beban listrik pada sistem. Untuk pengujian ini sistem diberi beberapa beban listrik yang berbeda antara lain lampu, kipas, setrika dan televisi. Pada hasil pengujian diatas diperoleh nilai daya yang merupakan perkalian tegangan dan arus $\boldsymbol{V} x \boldsymbol{I}=\boldsymbol{P}$. Pada pengukuran tersebut terdapat perbedaan pengukuran antara sensor PZEM dan multimeter. Persentase selisih tersebut dibanding hasil pengukuran merupakan nilai error atau kesalahan. Berikut adalah Tabel 2 hasil perbandingan pengukuran sistem dengan alat pembanding yaitu multimeter beserta error.

Tabel 2. Tabel pengukuran PZEM

\begin{tabular}{|c|c|c|c|c|c|c|c|c|}
\hline \multirow{2}{*}{ No. } & \multirow{2}{*}{ Beban } & \multicolumn{3}{|c|}{ Pengukuran sensor } & \multicolumn{3}{|c|}{ Pengukuran multimeter } & \multirow{2}{*}{$\begin{array}{c}\text { Error } \\
\text { Daya(\%) }\end{array}$} \\
\hline & & tegangan & arus & daya & tegangan & arus & daya & \\
\hline 1 & Lampu & $\mathrm{V}=188$ & $\mathrm{I}=0.06$ & $P=11.28$ & $\mathrm{~V}=187$ & $\mathrm{I}=0.063$ & $P=11.78$ & $4,2 \%$ \\
\hline 2 & Kipas Angin & $\mathrm{V}=189$ & $\mathrm{I}=0.15$ & $P=28.35$ & $\mathrm{~V}=188$ & $\mathrm{I}=0.154$ & $P=28.95$ & $2,0 \%$ \\
\hline 3 & Televisi & $\mathrm{V}=188$ & $\mathrm{I}=0.28$ & $P=52.64$ & $\mathrm{~V}=188$ & $I=0.283$ & $P=53.01$ & $0,7 \%$ \\
\hline 4 & Setrika & $\mathrm{V}=190$ & $\mathrm{I}=1.20$ & $P=228$ & $\mathrm{~V}=189$ & $\mathrm{I}=1.210$ & $\mathrm{~V}=228.7$ & $0,3 \%$ \\
\hline
\end{tabular}

Pada hasil pengukuran error diatas dapat diperoleh rata-rata error yaitu $\pm 1,8 \%$. Dapat dilihat juga bahwa semakin besar daya yang diukur semakin kecil error yang diperoleh.

Pengujian Aplikasi Android berisi serangkaian pengujian fungsi dan tombol pada aplikasi Sistem Monitoring Daya Listrik pada Kamar Kos. Pengujian aplikasi dilakukan menggunakan smartphone android. Berikut hasil dari pengujian kotak hitam yang telah dilakukan. Tabel 3 merupakan tabel hasil pengujian aplikasi menggunakan kotak hitam. 
Tabel 3. Hasil pengujian aplikasi android menggunakan kotak hitam

\begin{tabular}{|c|c|c|c|}
\hline Nama Pengujian & Bentuk Pengujian & Hasil yang Diharapkan & $\begin{array}{c}\text { Hasil } \\
\text { Pengujian } \\
\end{array}$ \\
\hline $\begin{array}{l}\text { Pengujian buka } \\
\text { aplikasi }\end{array}$ & Membuka aplikasi & Tampil halaman awal aplikasi & Berhasil \\
\hline $\begin{array}{c}\text { Pengujian masuk ke } \\
\text { home }\end{array}$ & Menekan tombol home & Tampil halaman utama aplikasi & Berhasil \\
\hline $\begin{array}{l}\text { Pengujian masuk ke } \\
\text { history }\end{array}$ & Menekan tombol history & Tampil halaman history aplikasi & Berhasil \\
\hline $\begin{array}{c}\text { Pengujian masuk ke } \\
\text { settings }\end{array}$ & Menekan tombol settings & Tampil halaman settings aplikasi & Berhasil \\
\hline $\begin{array}{c}\text { Pengujian kembali ke } \\
\text { menu }\end{array}$ & Menekan tombol back & Tampil halaman awal aplikasi & Berhasil \\
\hline $\begin{array}{c}\text { Pengujian } \\
\text { menampilkan daftar } \\
\text { kamar dan infonya } \\
\end{array}$ & Masuk ke halaman home & $\begin{array}{c}\text { Tampil daftar kamar beserta info } \\
\text { daya dan status relay }\end{array}$ & Berhasil \\
\hline $\begin{array}{l}\text { Pengujian } \\
\text { menampilkan detail } \\
\text { info } \\
\end{array}$ & $\begin{array}{l}\text { Menekan salah satu kolom } \\
\text { kamar }\end{array}$ & $\begin{array}{c}\text { Tampil detail total daya dan tarif } \\
\text { yang dikenakan }\end{array}$ & Berhasil \\
\hline $\begin{array}{c}\text { Pengujian } \\
\text { memutuskan } \\
\text { sambungan listrik } \\
\text { pada salah satu kamar }\end{array}$ & $\begin{array}{c}\text { Menekan tombol on/off pada } \\
\text { kolom kamar }\end{array}$ & $\begin{array}{c}\text { Sambungan listrik pada sistem akan } \\
\text { tersambung/terputus }\end{array}$ & Berhasil \\
\hline $\begin{array}{l}\text { Pengujian melihat } \\
\text { riwayat pemakaian }\end{array}$ & $\begin{array}{c}\text { Masuk halaman history lalu } \\
\text { memilih kamar dan tanggal } \\
\text { yang diinginkan }\end{array}$ & $\begin{array}{c}\text { Tampil daftar pemakaian listrik } \\
\text { harian beserta grafik }\end{array}$ & Berhasil \\
\hline $\begin{array}{c}\text { Pengujian mengatur } \\
\text { otomatisasi relay }\end{array}$ & $\begin{array}{c}\text { Menggeser tombol otomatisasi } \\
\text { relay }\end{array}$ & $\begin{array}{c}\text { Sistem bekerja otomatis } \\
\text { menyalakan/mematikan relay }\end{array}$ & Berhasil \\
\hline $\begin{array}{l}\text { Pengujian mengatur } \\
\text { batas daya maksimal }\end{array}$ & Memasukkan nilai batas daya & Menyimpan nilai batas daya & Berhasil \\
\hline $\begin{array}{l}\text { Pengujian mengatur } \\
\text { tarif }\end{array}$ & Memasukkan nilai tarif & Menyimpan nilai tarif & Berhasil \\
\hline
\end{tabular}

\section{Kesimpulan}

Berdasarkan hasil pengujian yang dilakukan terhadap sistem monitoring daya listrik pada kamar kos berbasis android dengan menggunakan NodeMCU dan Firebase, maka dapat disimpulkan sebagai berikut.

1. Sistem ini dapat memantau daya yang dipakai saat itu juga pada tiap kamar kos yang terpasang perangkat menggunakan smartphone Android.

2. Sistem mampu menyimpan data riwayat pemakaian daya pada database Firebase.

3. Aplikasi sistem Android mampu mengontrol sambungan aliran listrik pada tiap kamar.

4. Sistem dapat diatur secara otomatis untuk memutuskan daya berdasarkan besarnya daya yang telah ditetapkan pada pengaturan di Aplikasi Sistem.

5. Sistem memiliki kesalahan pembacaan daya rata-rata sebesar $\pm 1,8 \%$.

\section{Daftar Pustaka}

[1] A. M. Syafar, "Kendali Perangkat Listrik dan Monitoring Daya pada MCB Berbasis TCP/IP", Jurnal INSTEK UIN Alauddin Makassar, vol. 1, no. 1, 2016. 
[2] Zakaria, A. Muid, Ilhamsyah, "Prototype Sistem Monitoring Masa Sewa Kamar Kos Berbasis Mikrokontroler", Jurnal Coding Sistem Komputer UNTAN, vol. 3, no. 3, hlm. 35-44, 2015.

[3] I. S. Hudan, T. Rijianto, "Rancang Bangun Sistem Monitoring Daya Listrik pada Kamar Kos Berbasis Internet of Things (IoT)", Jurnal Universitas Negeri Surabaya, vol. 8, no. 1, hlm. 91-99, 2019.

[4] Z. Ramadhan, S. R. Akbar, G. E. Setyawan, "Implementasi Sistem Monitoring Daya Listrik Berbasis Web dan Protokol Komunikasi Websocket", Jurnal PTIIK UB, vol.3, no. 1, hlm. 205-211, 2019.

[5] I G. P. M. E. Putra, I. A. D. Giriantari, L. Jasa, “Monitoring Menggunaan Daya Listrik Sebagai Implementasi Internet of Things Berbasis Wireless Sensor Network", Jurnal Elektro UNUD, vol. 16, no. 3, hlm. 50-55, 2017.

[6] V. Rahmawati, "Sistem Pengendali Pintu Berbasis Web menggunakan NodeMCU 8266", STMIK AKAKOM Yogyakarta, 2017.

[7] Anonim, "PZEM-004T," 2018. [Online]. Available: https://innovatorsguru.com/acdigital-multifunction-meter-using-pzem-004t. [Accessed: 01-Mei-2019]

[8] Rusmadi, Dedy, Mengenal Komponen Elektronika, Bandung: Pionir, 2009.

[9] Aditya Orba, "Ramadhan Pembangunan Modul Penunjang Pembelajaran di Kelas Untuk Aplikasi Brawijaya Messenger Dengan Platform Firebase", Juranl PTIIK UB, vol. 2, no. 4, hlm. 1630-1637, 2018.

[10]N. Safaat, Pemograman Aplikasi Mobile Smartphone dan tablet PC Berbasic Android, Bandung: Informatika, 2011. 